\title{
O SANTO VISITA 0 REI: FESTIVIDADE AFRORRELIGIOSA EM SÃO JOÃO DE PIRABAS E 0 COMPLEXO DA ENCANTARIA NA AMAZÔNIA ORIENTAL
}

Thayanne Tavares Freitas (D)

Universidade Federal do Rio Grande do Sul I Porto Alegre - RS - Brasil

Hermes de Sousa Veras (D)

Universidade Federal do Rio Grande do Sul I Porto Alegre - RS - Brasil 
No dia 20 de janeiro, afrorreligiosos se mobilizam para cultuar Rei Sabá, entidade encantada que, segundo uma de muitas histórias, se petrificou na praia do Castelo, região insular da cidade São João de Pirabas, localizada no nordeste do estado do Pará, na Amazônia oriental. Embarcações saem da cidade para a ilha, levando afrorreligiosos, pessoal de apoio e outros interessados em assistir a festividade e dela participar. O ápice da atividade é quando se entrega oferendas na pedra onde se reconhece o encantado. $\mathrm{O}$ ato é acompanhado de giras coletivas, juntando as comunidades de terreiros participantes. Por acontecer no dia do mártir da igreja católica, São Sebastião, os afrorreligiosos celebram-no em uma missa no dia anterior, na paróquia de São João Batista. Em 2019, o Templo de Umbanda Oxóssi e Mamãe Oxum, liderado por Mãe Rita, levou um andor em forma de barquinha, com a imagem de São Sebastião para a pedra do Rei Sabá (Rei Sebastião), assim, o santo se encontrou com o rei encantado, eclodindo na multiplicidade dessa entidade.

Todas essas ações ocorrem no Monumental Místico do Rei Sabá, que foi construído pelo prefeito Bosco Moisés em 2002 (cf. VergolinoHenry 2008), acrescentando uma base sob a pedra e construindo imagens em tamanho humano de Iemanjá e das encantadas Toia Jariana, Cabocla Mariana e Zé Raimundo. Com o tempo, a ação das águas e outras intempéries, as imagens foram se quebrando. Dona Caçula, genitora de Mãe Rita, e o próprio Pai Sival contam que a ação de Bosco Moisés foi arquitetada junto a Maria Pajé, uma antiga mãe de santo e pajé que atuou na região. Tudo foi feito para que Rei Sabá voltasse para a praia do Castelo, pois, segundo contam, ele estava se ausentando por conta do descaso para com a sua festa e o seu culto. As ações do ex e do atual prefeito e dos afrorreligiosos buscam reforçar a presença do encantado, sempre ameaçada quando não recebe a atenção e o cuidado demandado por ele.

Em 2018, as imagens do monumental místico estavam avariadas. Iemanjá ainda estava inteira, talvez por sua posição em relação ao movimento das águas, porém Cabocla Mariana tinha seus braços partidos e apresentava desgaste na tinta. Da imagem de Zé Raimundo restavam apenas resquícios do que teriam sido os pés. De Toia Jarina, nem os pés jaziam ali onde era seu monumento, resistindo somente a base de concreto do mesmo tipo que apoia Rei Sabá e as outras imagens. A partir da mobilização dos afrorreligiosos, foram 
conseguidas novas imagens, instaladas ainda em janeiro de 2019. Essa mobilização coletiva está imbricada aos propósitos de aumentar o reconhecimento de Rei Sabá na geografia afro-brasileira, mas também entre curiosos e apreciadores da "cultura", assim como pretende atrair turistas interessados nesse tipo de atração religiosa-cultural. A encantaria de Rei Sabá nunca saiu desse plano de ação política. Para atrair o encantado de volta, deixar a sua festa novamente bonita e atrativa para ele e outras pessoas, afrorreligiosos se mobilizaram com o poder público local. Portanto, essa política é uma extensão de outra, a cosmopolítica (Stengers 2018) encantada.

O dia 20 de janeiro de 2019 é evocado na sequência fotográfica feita com planos que trazem a chegada dos terreiros, do andor de São Sebastião e a sua levada para a pedra (Figuras $1 \mathrm{a}$ 10). Nesse ínterim, a gira coletiva é apresentada como uns dos momentos da celebração ao santo e ao encantado. A presença da TV Liberal, filial da TV Globo, mostra a cobertura midiática, quando foram entrevistados Pai Sival e Mãe Rita. Na Figura 9, filhos de santo do Templo de Umbanda Oxóssi e Mamãe Oxum carregam o andor, enquanto uma mulher posa na pedra do Rei Sabá, vestida com uma saída de praia. Portanto, no mesmo plano, vemos na composição, diversos usos deste espaço. A festividade atrai públicos afrorreligiosos, mas também turistas e pessoas curiosas com o que é apontado como cultura e história local, a partir da prefeitura do município e algumas lideranças afrorreligiosas.

Esse dia marca São João de Pirabas na geografia afro-brasileira como o lugar de morada do encantado Rei Sabá. Essa geografia, sem que esqueçamos de suas matizes e referenciais indígenas, fazem parte do complexo da encantaria, isto é, todas as formas de lidar com os encantados, esses seres que jamais passaram pela experiência da morte, se encantando, apresentando-se para as pessoas em rituais de pajelança, umbanda, tambor de mina, mina nagô e outras religiões. Esses seres possuem territórios, sendo donos dos fundos das águas, das ilhas e das praias. Além de essa territorialidade implicar uma relação de respeito com o território e o ser, também funciona como portal para entrar em outros mundos, que são as encantarias e os seus reinos. Este ensaio, portanto, está em diálogo com outras pesquisas realizadas junto à encantaria na Amazônia oriental (Silva 2018).

Essas imagens foram expostas em mostra fotográfica da XIII Reunião de Antropologia do Mercosul, em Porto Alegre. 


\section{REFERÊNCIAS}

Silva, J. S. 2018. Encantaria - na Amazônia oriental, in Uwa'Kürü: dicionário analítico: v. 3. Editado por G. R. Albuquerque \& A. S. Pacheco, pp. 56-75. Rio Branco: Nepan Editora.

Stengers, I. 2018. A proposição cosmopolítica. Revista do Instituto de Estudos Brasileiros (69): 442-464. DOI: https://doi.org/10.11606/issn.2316-901X.v0i69p442-464

Vergolino-Henry, A. 2008. Um encontro na encantaria: notas sobre a inauguração do 'Monumental Místico Rei Sabá', in Pajelanças e religiões africanas na Amazônia. Editado por R. H. Maués \& G. M. Villacorta, pp. 139-148. Belém: EDUFPA. 


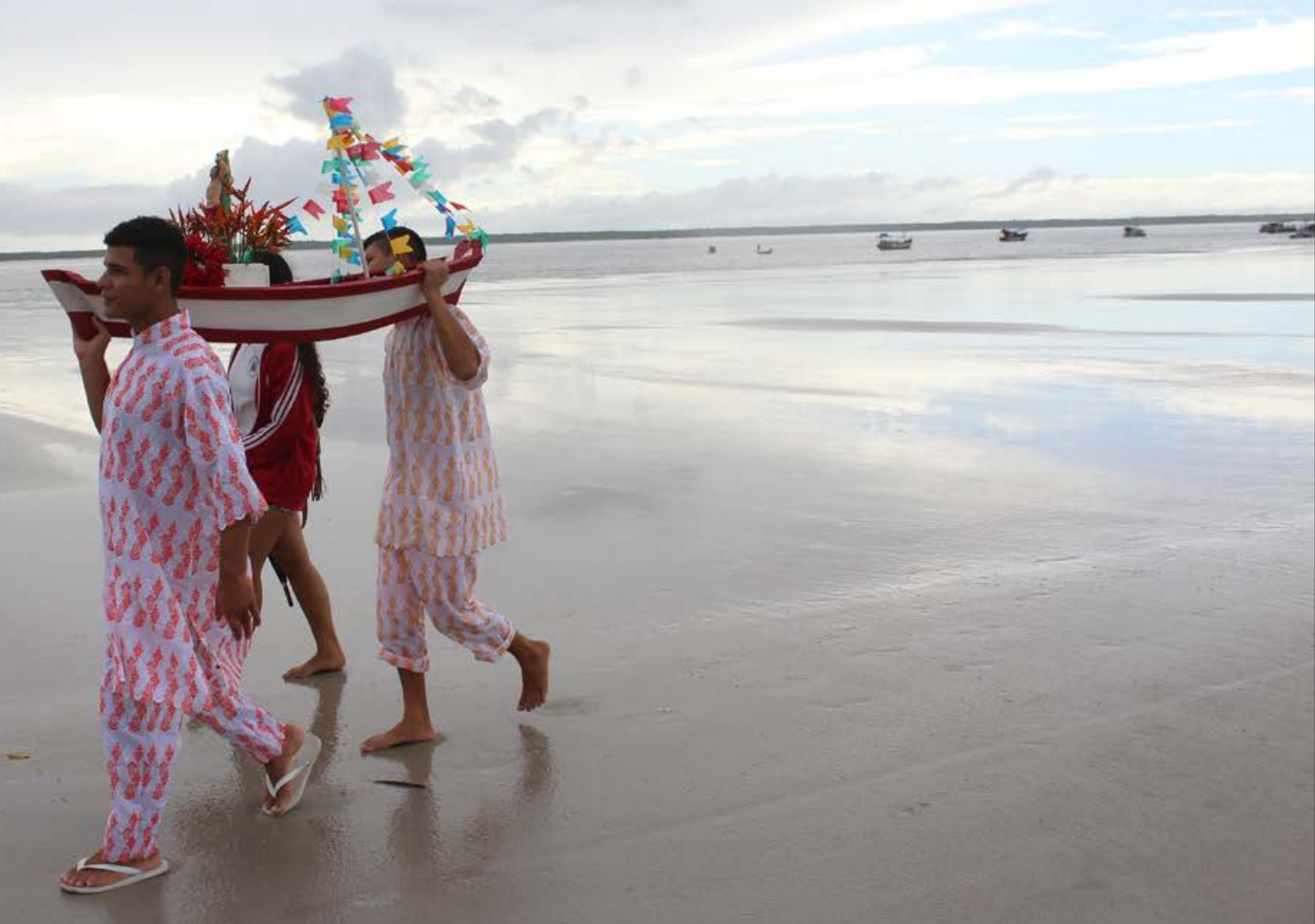

Figura 1 - Jefferson e Douglas (Pai Pequeno) carregando o andor de São Sebastião na praia da Fortaleza. Foto: Thayanne Tavares F. (2019). 


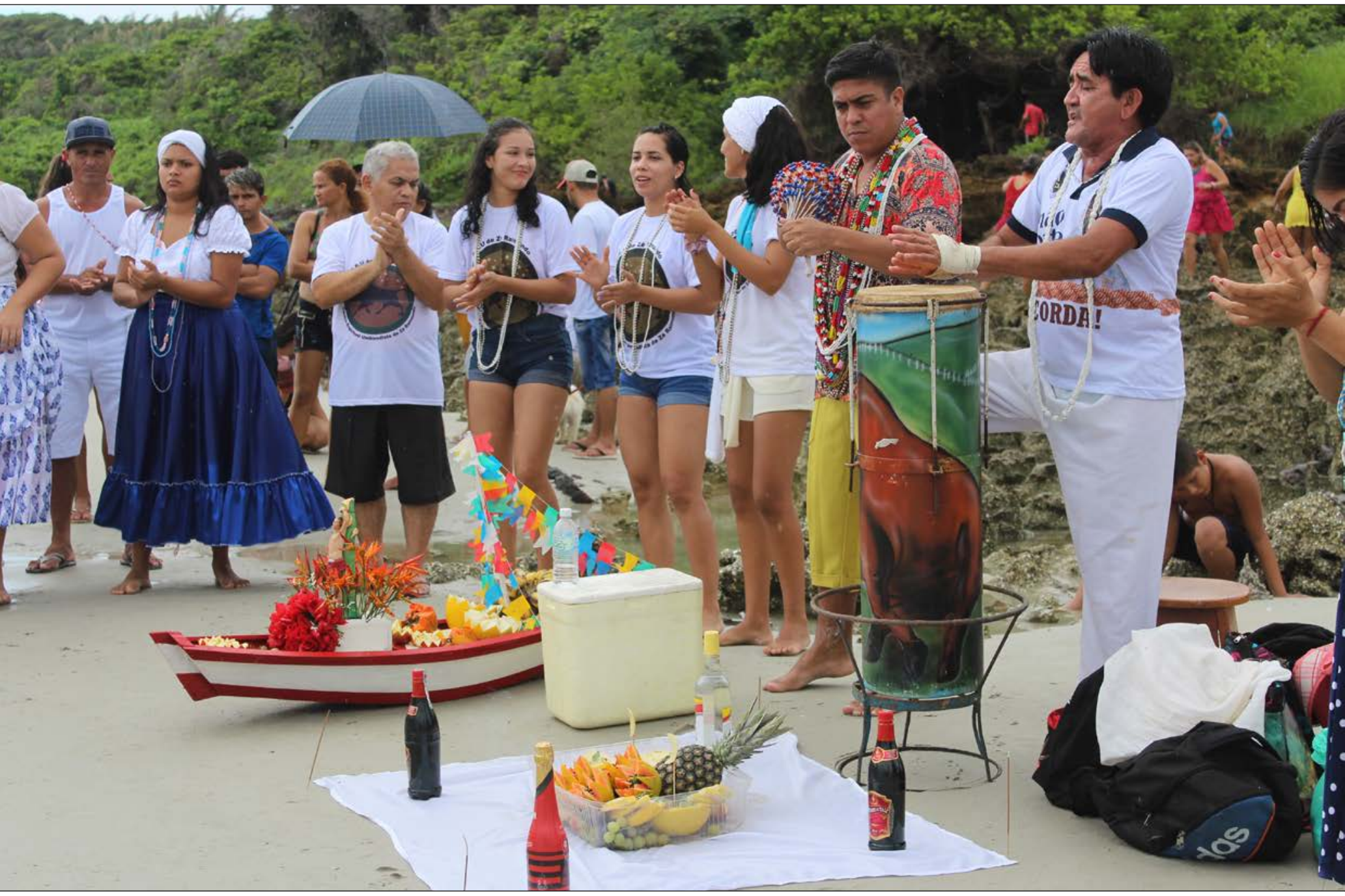

Figura 2 - Gira para os encantados na praia do Castelo. Foto: Thayanne Tavares F. (2019). 


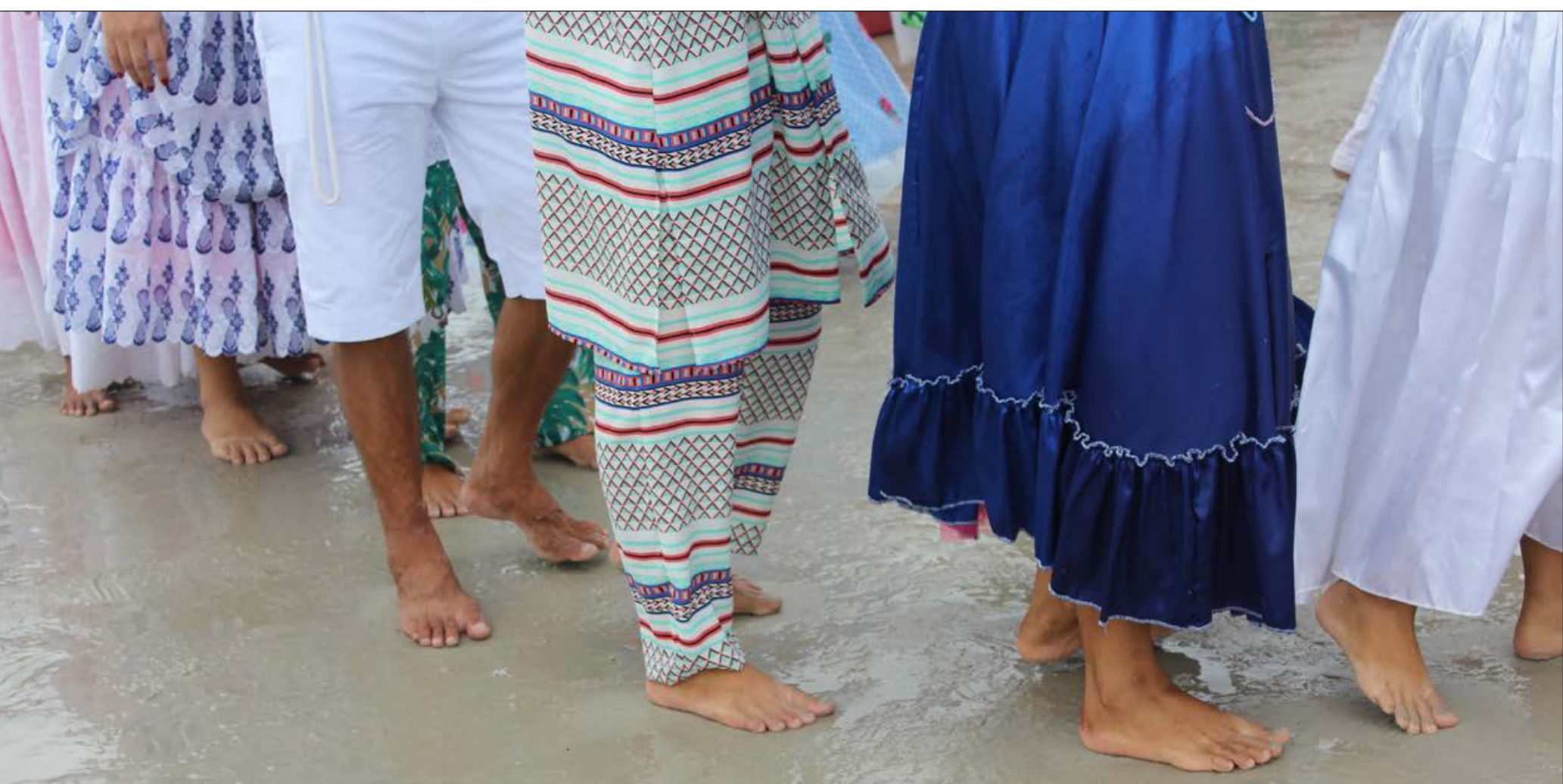

Figura 3 - Gira encantada. Foto: Thayanne Tavares F. (2019). 


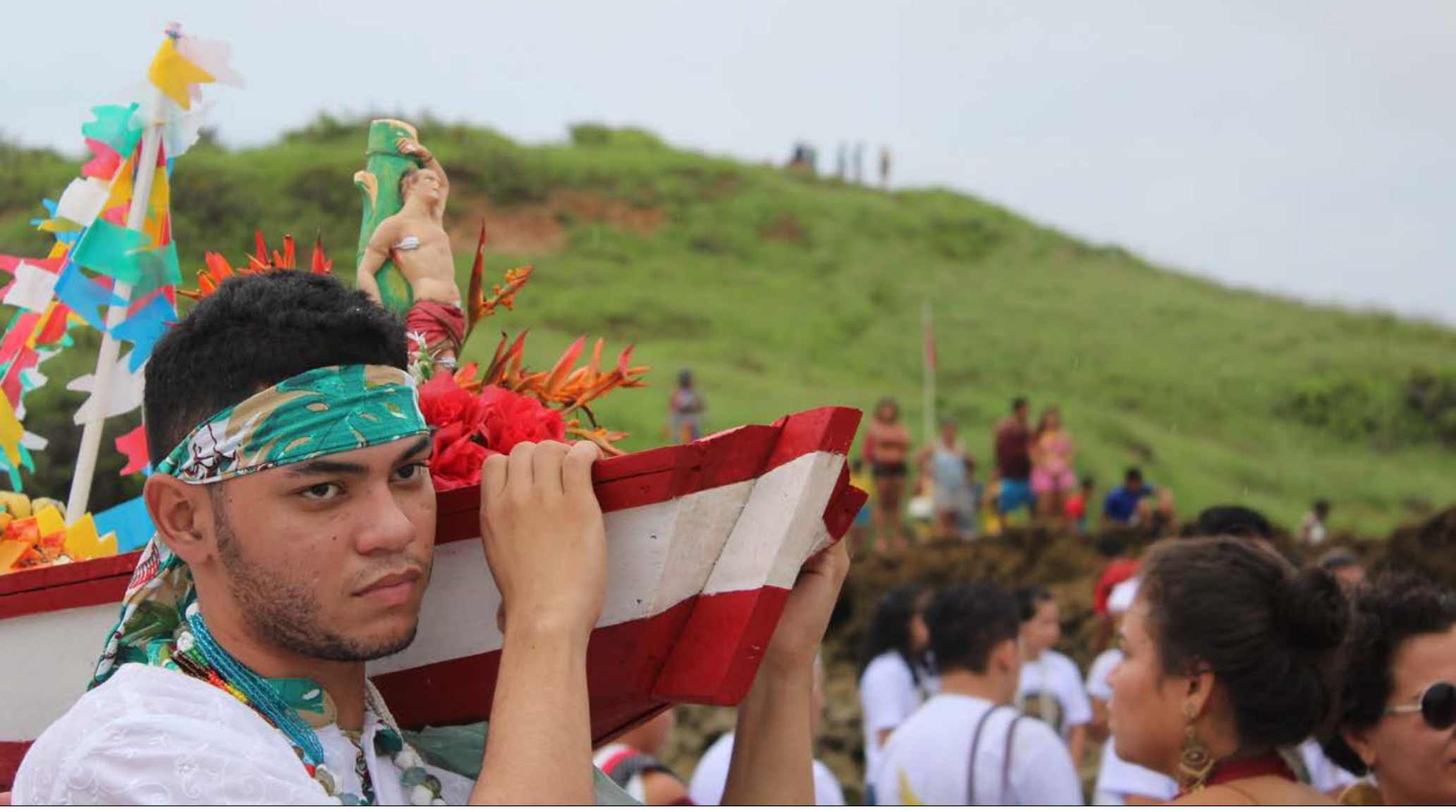

Figura 4 - Ednelson carregando o andor do santo, logo mais o santo encontrará o rei encantado. Foto: Thayanne Tavares F. (2019). 


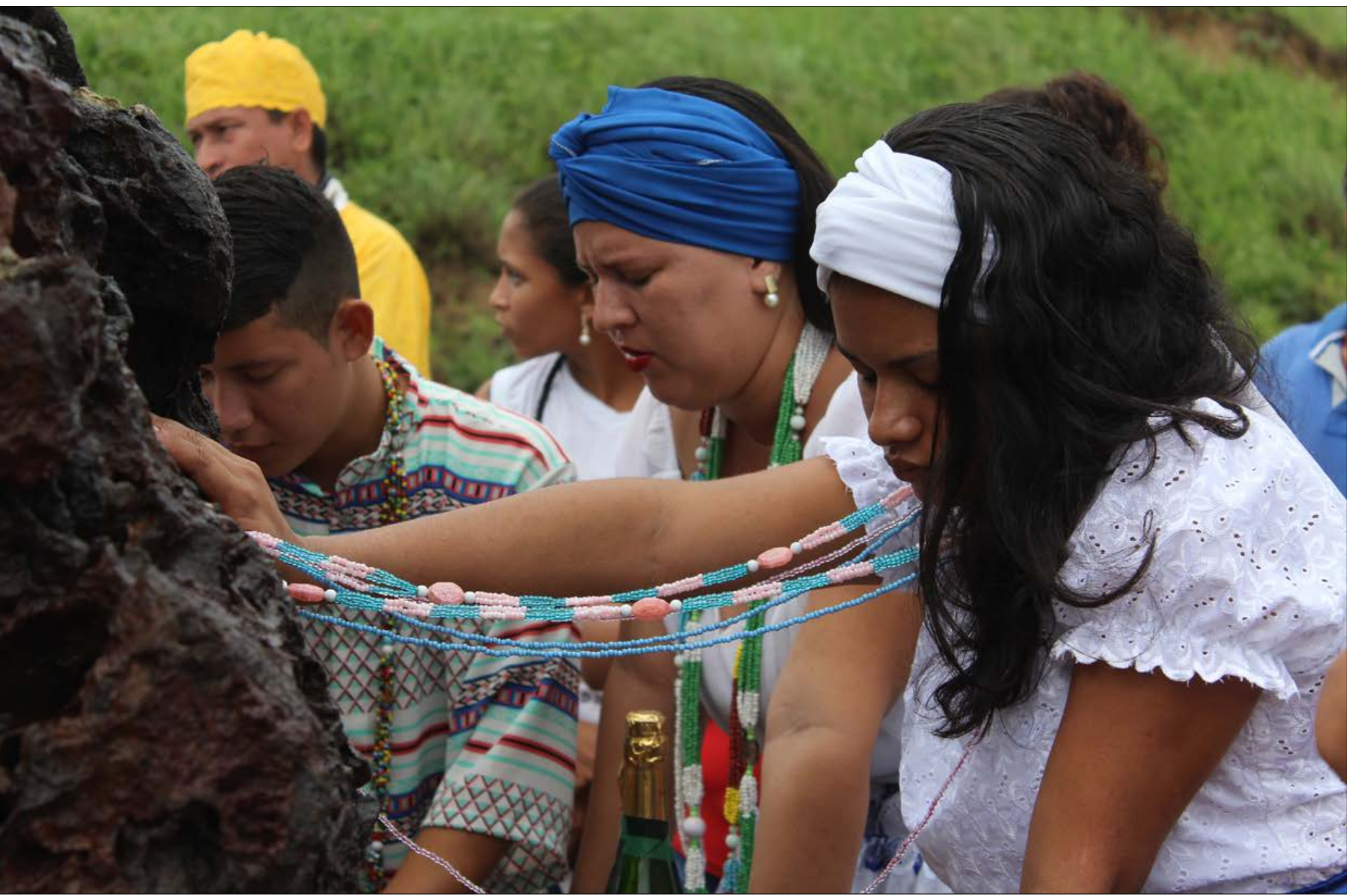

Figura 5 - Filhas de santo pedindo licença e bênçãos para Rei Sabá e toda a sua encantaria. Foto: Thayanne Tavares F. (2019). 


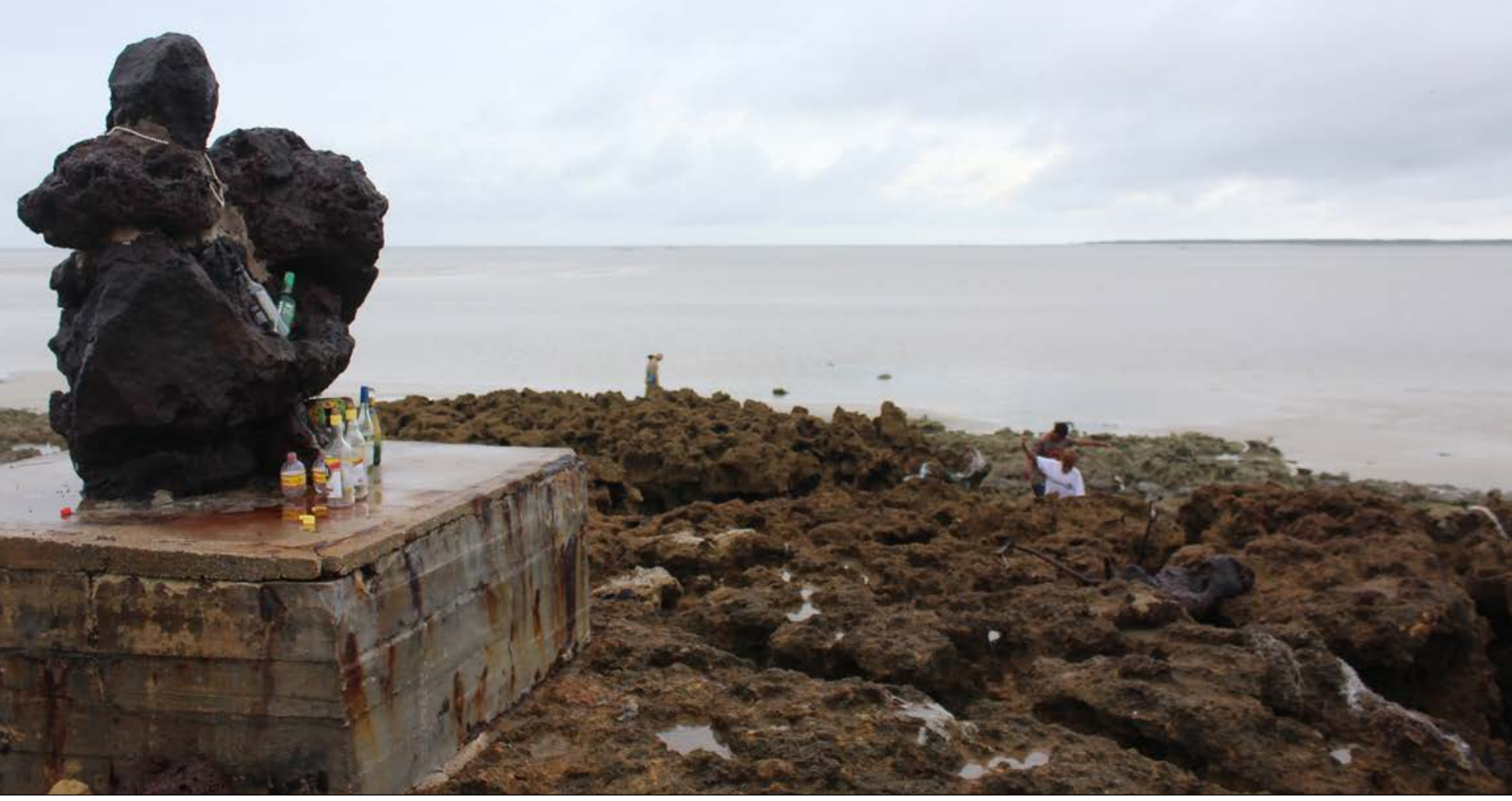

Figura 6 - Pedra do Rei Sabá sobre uma base de concreto e imersa em um sítio paleontológico denominado de Formação Pirabas. Foto: Thayanne Tavares F. (2019). 


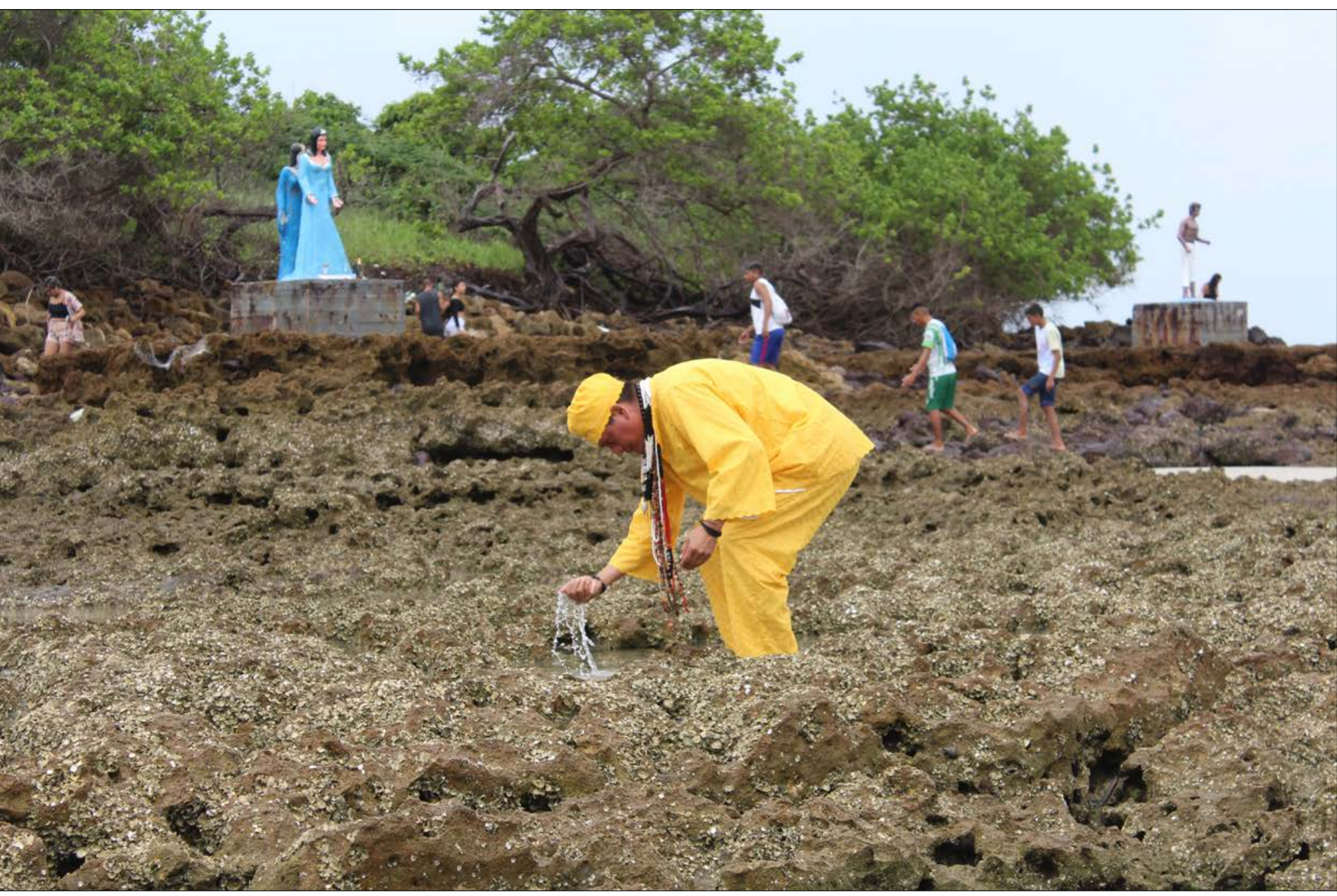

Figura 7 - Pai Sival apanhando um pouco de água para abençoar a sua cabeça (croa, coroa). Foto: Thayanne Tavares F. (2019). 


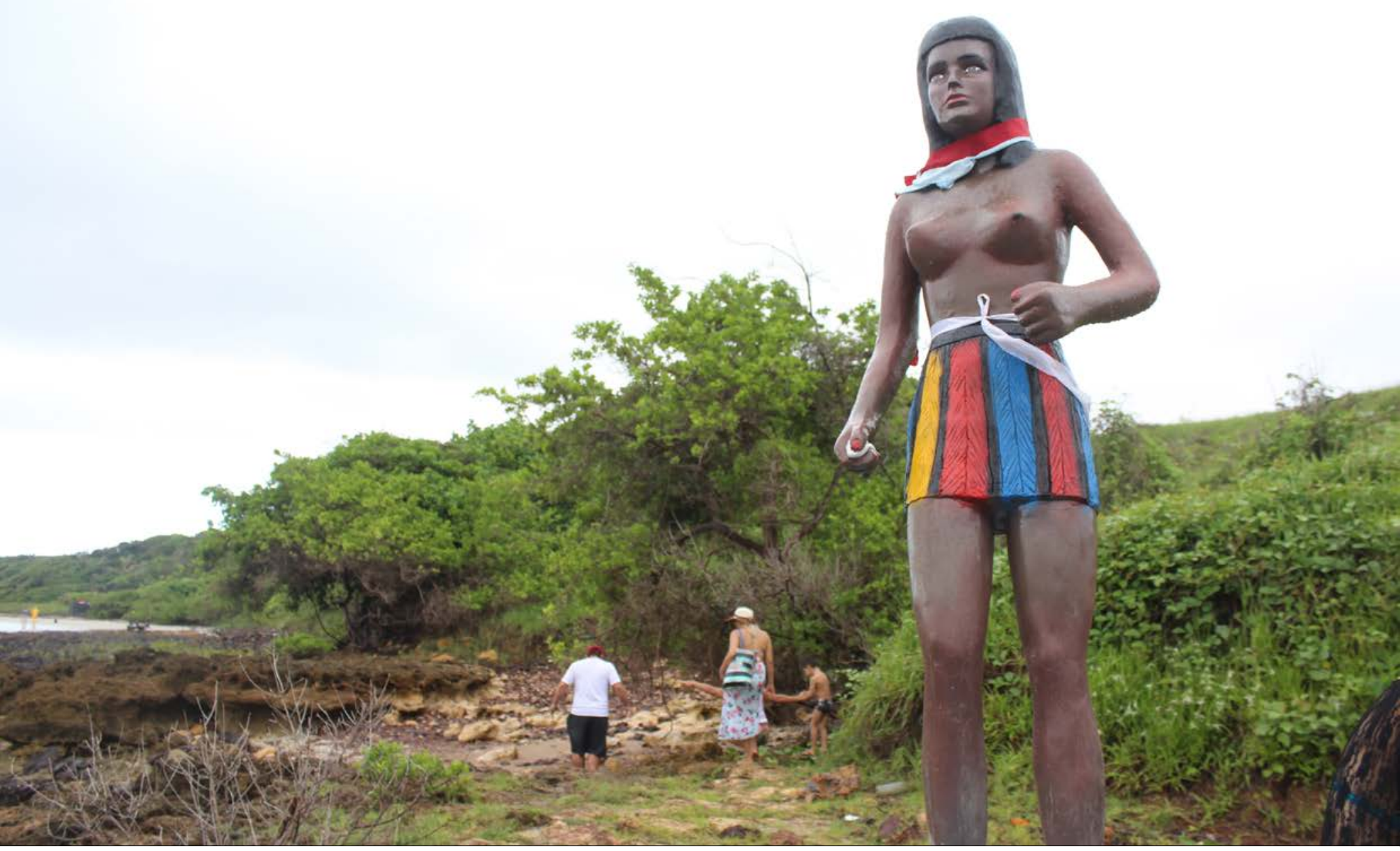

Figura 8 - Toia Jarina, filha encantada de Rei Sebastião. Foto: Thayanne Tavares F. (2019). 


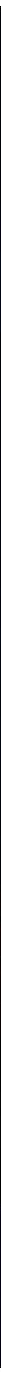

Figura 9 - O santo encontra o rei. Foto: Thayanne Tavares F. (2019). 


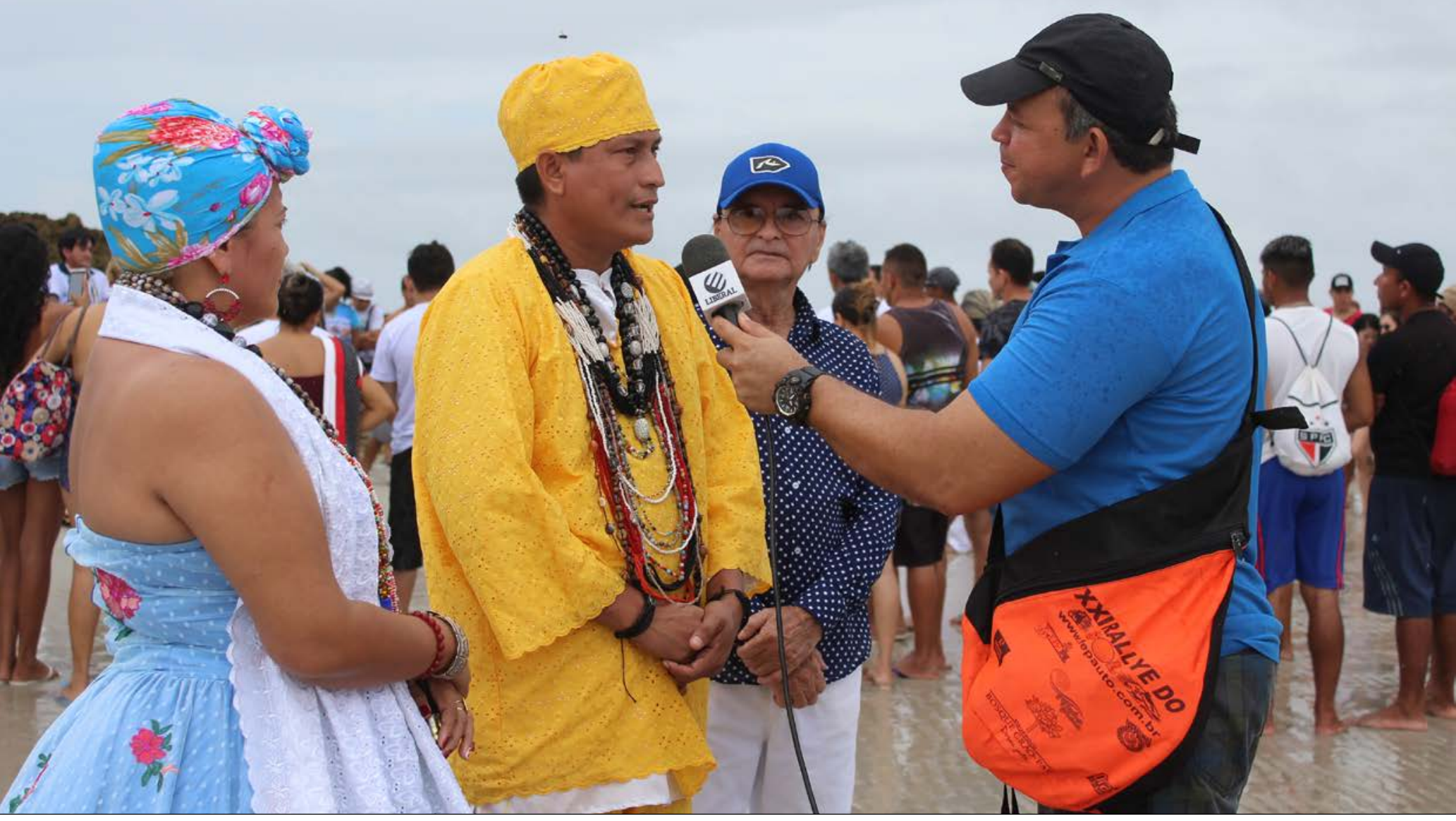

Figura 10 - Pai Sival e Mãe Rita sendo entrevistados pelo repórter da TV Liberal. Foto: Thayanne Tavares F. (2019). 